\title{
Organic versus integrated apple growing: II. differences in fruit quality parameters
}

\author{
Nagy, P.T., Szabó, Z., Nyéki, J., Gonda, I. \& Holb, I. \\ University of Debrecen, Centre of Agricultural Sciences, Faculty of Agronomy, Böszörményi u. 138. \\ Debrecen, H-4032, Hungary
}

\begin{abstract}
Summary: The aim our study was to establish whether significant differences in nutrients uptake and quality of fruit exist between organic and integrated grown apples. The study was performed at the orchard Fruit Research Station, University of Debrecen, at Debrecen-Pallag during 2002-2004. Diameter (mm), weight (g), firmness (N/ $\left.\mathrm{cm}^{2}\right)$, dry matter (\%) and Vitamin C in fruit were determined. Diameter data showed that the size of apples strongly depended on cultivars and organic apples were larger than integrated ones. Moreover, the effect of year and species strongly affected the apple diameter, size and weight. Measured data of firmness were good agreement in data of diameter and weight. Larger fruits have lower values of firmness due to the structure of fruit flesh. Dry matter content of apples varied between 14.66 and 18.07 in integrated, and 12.87 and 17.29 in organic apples according to cultivars. Values were affected by years and cultivars. From results it was evident that the dry matter content of apples affected by production system. It was lower in organic samples than integrated ones. Vitamin C content of apples was stronger affected by species and years than production system.
\end{abstract}

Key words: integrated, organic, fruit analyses, diameter, weight, firmness, dry matter and vitamin C

\section{Introduction}

Consumer demand for organically grown produce has increased dramatically over the past decade, most likely because of the perceived benefits to the environment and human health. A major component of organic production is providing organic sources of nutrients to promote plant growth as well as sustain soil quality. Organic nutrition of plants can present opportunities and challenges to the grower (Rosen and Allan, 2007). Contributing to the increasing consumer demand for healthier and more environmentally sustainable agricultural products, there has been a great expansion in the number of growers and the total land area utilizing organic and integrated farm management systems in apple (Malus domestica Borkh.) orchards around the world. Moreover, both organic and integrated production systems strive towards sustainability by minimizing environmental degradation and improving soil quality, while maximizing productivity as well as economic returns (Reganold et al., 2001). Organic agriculture has gained international attention and the number of organic farms and the area of organic fruit production has been increased starting the nineties mostly in USA (Granatstein, 2000).

In other countries, particularly New Zealand and many European Union (EU) member-states, integrated farm management has become the standard agricultural practice, while conventional management is largely being phased out, with the belief that an integrated agricultural system represents the middle ground between the constraints of certified organic production and the negative impacts of conventional agriculture (Sansavini, 1997; Morris and Winter, 1999). According to increasing costumer demand, efforts of healthy lifestyle within the last decade there have been a number of excellent reviews about contrasting organic with integrated or conventionally grown fruits for quality claims (Lester, 2006). I think a common thread to compare these growing systems is the huge variability in the available data. In most cases, differences in location, climatic conditions, fruit nutrition, water management, pest practices, varieties, fruit maturity and harvest dates, pre- and postharvest handling can individually and collectively contribute to the observed variability and opposing conclusions.

In spite of the enormous number of publication, Woese's lament: "what is noticeable, as in the case with apples, that differences between varieties had a far greater influence on fruit quality attributes than did the different cultivation systems" is not at all cleared Woese et al., 1997).

Therefore, the purpose of this study was to measure the effects of organic and integrated apple production systems on fruit quality among Hungarian conditions.

\section{Materials and methods}

Characteristics of examined apple orchard, applied nutritional management, results of soil and leaf 
examination can be read in our another publication: Organic versus integrated apple growing: differences of fruit nutrition: discussion of soil and leaf analytical investigation. In this paper we are focusing the fruit quality examinations only.

At ripening stage from each studied cultivars 100 medium-sized apples was used for harvest measurements.

For consuming quality of fruits the following parameters were measured:

Diameter ( $\mathrm{mm})$ was measured by digital calliper.

Weight $(\mathrm{g})$ was measured by analytical scale with $0,0001 \mathrm{~g}$ punctuality.

Firmness $\left(\mathrm{N} / \mathrm{cm}^{2}\right)$ was measured by hand penetrometer (Bishop).

Dry matter (\%) was measured by analytical scale with $0.0001 \mathrm{~g}$ punctuality.

Vitamin C (mg/100g fresh weight) in fruit was determined by HPLC. For determination Spherisorb ODS C18 $(15 \times 4.6$, $5 \mathrm{~m}$ ) column was used (eluent was: $0.01 \%$-os $\mathrm{K}_{2} \mathrm{SO}_{4}$ $(\mathrm{pH}=2.6)$; flow rate was: $1 \mathrm{ml} / \mathrm{min}$ ) and UV-VID DAD detector with wavelength at $245 \mathrm{~nm}$ for identification.

Health (\%) manually selected and controlled healthy fruits from 100 fruits.

\section{Results and discussion}

Studied fruit qualifying parameters were shown in Tables 1 and 2.

Diameter data showed that the size of apples strongly depended on cultivars and organic apples were larger than

Table 1. Fruit qualifying parameters I. (means of three-year)

\begin{tabular}{|l|l|c|c|c|}
\hline System & Cultivar & $\begin{array}{c}\text { Diameter } \\
(\mathbf{m m})\end{array}$ & $\begin{array}{c}\text { Weight } \\
(\mathbf{g})\end{array}$ & $\begin{array}{c}\text { Firmness } \\
\left(\mathbf{N} / \mathbf{c m}^{2}\right)\end{array}$ \\
\hline \multirow{5}{*}{ Integrated } & Jonagold & 73.20 & 178.3 & 75.61 \\
& Mutsu & 75.60 & 193.7 & 70.22 \\
& Idared & 71.00 & 196.3 & 68.82 \\
& Red Elstar & 67.51 & 140.2 & 78.62 \\
& Egri Piros & 72.22 & 157.6 & 66.0 \\
& Reka & 66.91 & 114.4 & 73.31 \\
& Remo & 67.51 & 137.4 & 67.30 \\
\cline { 2 - 5 } & Mean & 70.56 & 159.70 & 71.41 \\
& SD & 3.35 & 31.03 & 4.61 \\
& LSD5\% & 2.48 & 22.98 & 3.42 \\
\hline \multirow{5}{*}{ Organic } & Jonagold & 79.57 & 203.4 & 72.11 \\
& Mutsu & 82.54 & 223.0 & 64.42 \\
& Idared & 80.76 & 162.1 & 59.70 \\
& Red Elstar & 76.31 & 163.3 & 74.31 \\
& Egri Piros & 70.39 & 153.4 & 55.60 \\
& Reka & 70.71 & 133.6 & 67.42 \\
& Remo & 65.40 & 126.9 & 69.83 \\
\cline { 2 - 5 } & Mean & 75.10 & 166.53 & 66.20 \\
& SD & 6.38 & 35.13 & 6.75 \\
& LSD5\% & 4.73 & 26.03 & 5.00 \\
\hline Integrated & Mean & $\mathbf{7 2 . 8 3}$ & $\mathbf{1 6 3 . 1 1}$ & $\mathbf{6 8 . 8 1}$ \\
vs. & SD & $\mathbf{5 . 4 3}$ & $\mathbf{3 2 . 0 4}$ & $\mathbf{6 . 1 8}$ \\
Organic & LSD5\% & $\mathbf{2 . 8 5}$ & $\mathbf{1 6 . 7 8}$ & $\mathbf{3 . 2 3}$ \\
& & & & \\
\hline
\end{tabular}

Table 2. Fruit qualifying parameters II. (means of three-year)

\begin{tabular}{|l|l|c|c|c|}
\hline System & Cultivar & $\begin{array}{c}\text { Dry matter } \\
(\boldsymbol{\%})\end{array}$ & $\begin{array}{c}\text { Vitamin C } \\
\text { (mg/100g } \\
\text { fresh weight) }\end{array}$ & $\begin{array}{c}\text { Health } \\
(\boldsymbol{\%})\end{array}$ \\
\hline & Jonagold & 14.66 & 4.93 & 88.2 \\
& Mutsu & 17.12 & 3.87 & 76.8 \\
& Idared & 16.50 & 8.45 & 84.3 \\
& Red Elstar & 18.07 & 6.34 & 88.6 \\
Integrated & Egri Piros & 14.38 & 6.32 & 90.2 \\
& Reka & 17.67 & 6.36 & 91.5 \\
& Remo & 17.70 & 7.64 & 96.3 \\
\hline & Mean & 16.59 & 6.27 & 87.99 \\
& SD & 1.50 & 1.54 & 6.13 \\
& LSD5\% & 1.11 & 1.14 & 4.54 \\
\hline & Jonagold & 14.62 & 5.64 & 44.9 \\
& Mutsu & 14.92 & 9.16 & 57.4 \\
& Idared & 13.83 & 6.34 & 60.1 \\
& Red Elstar & 17.29 & 5.99 & 49.7 \\
Organic & Egri Piros & 12.87 & 5.64 & 49.6 \\
& Reka & 15.75 & 6.34 & 65.9 \\
& Remo & 17.10 & 7.75 & 84.2 \\
& Mean & 15.20 & 6.69 & 58.83 \\
& SD & 1.63 & 1.30 & 13.29 \\
& LSD5\% & 1.21 & 0.96 & 9.85 \\
\hline Integrated & Mean & $\mathbf{1 5 . 8 9}$ & $\mathbf{6 . 4 8}$ & $\mathbf{7 3 . 4 1}$ \\
vs. & SD & $\mathbf{1 . 6 7}$ & $\mathbf{1 . 3 9}$ & $\mathbf{1 8 . 1 0}$ \\
Organic & LSD5\% & $\mathbf{0 . 8 7}$ & $\mathbf{0 . 7 3}$ & $\mathbf{9 . 4 8}$ \\
& LSD & & \\
\hline
\end{tabular}

integrated ones. It can be explained by fruit loaded of trees. Fewer fruits resulted higher size in the organic orchard part.

Obtained data of fruit weight confirmed this statement. Moreover, the effect of year and species strongly affected the apple diameter, size and weight. Measured data of firmness were good agreement in data of diameter and weight. Larger fruits have lower values of firmness due to the structure of fruit flesh.

Dry matter content of apples varied between 14.66 and 18.07 in integrated, and 12.87 and 17.29 in organic apples according to cultivars. Values were affected by years (data not shown) and cultivars. From results it was evident that the dry matter content of apples affected by production system. It was lower in organic samples than integrated ones.

Vitamin C content of apples was stronger affected by species and years than production system. Significant differences found in apple total vitamin $\mathrm{C}$ content among cultivars. Moreover, our results confirmed earlier results (Weibel et al., 2000) whereas did not find significant differences in apple vitamin $\mathrm{C}$ content between the two production systems.

Healthy fruits number strongly affected by years, cultivars and production systems also (Table 2., Figures 1-2.). Among integrated conditions approximately $88 \%$ of apples were healthy, while this ratio was approximately $59 \%$ in organic production system. This large, significant difference follows from the different training method. The significant difference of the number of healthy fruits due to several cropping differences (e.g. plant protection, nutrition). 


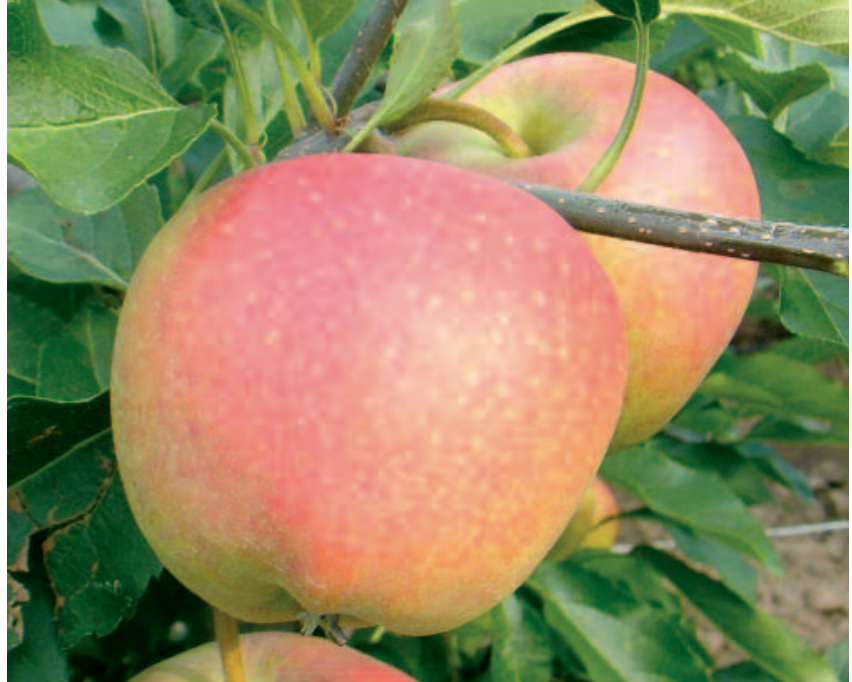

Figure 1. Integrated apples

\section{Conclusions}

Based on our small-scale research may suggest that there are significant differences between organic and integrated production systems regarding fruit nutritional aspects.

In conclusion, from results it is very hazardous to state that organic fruits provide greater health benefits than integrated ones but we suggest that these comparison studies should be expand. Similar studies have to carry out in more and more orchards, among different conditions (climatic, orchard density, rootstocks, nutritional management etc.).

The real benefit of these comparisons is that they will recognize and establish the production input weakness and strengths that affect nutrition, so that changes can be made to improve both organic and integrated fruit growing produce.

\section{Acknowledgements}

Thanks to OM-00042/2008 project for financial assistance. The study was supported by the NKTH programme (OM-00227/2008) and by the research programme of OTKA (K 78399) as well as by a János Bolyai Research Fellowship.

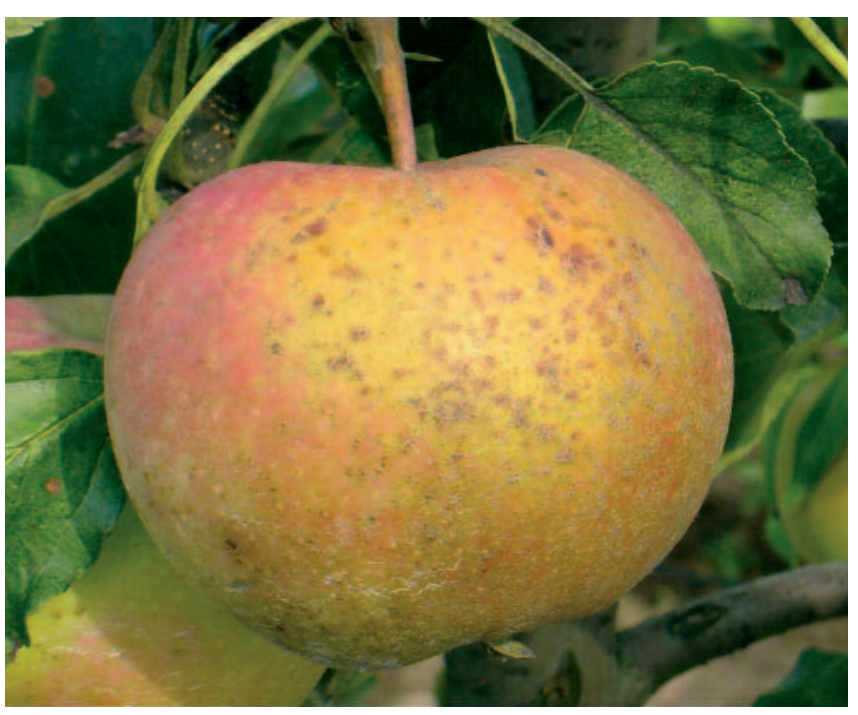

Figure 2. Organic apples

\section{References}

Reganold, J.P., J.D. Glover, P.K. Andrews \& Hinman, H.R. (2001): Sustainability of three apple production systems. Nature, 410: 926-929.

Granatstein, D. (2000): Tree fruit production with organic farming methods.http://organic.tfrec.wsu.edu/OrganicIFP/OrganicFruit Production/OrganicMgt.pdf

Lester, G. E. (2006): Organic versus conventionally grown produce:quality differences, and guidelines for comparison studies. HortScience, 41 (2): 296-299.

Morris, C. \& Winter, M., (1999): Integrated farming systems: the third way for European agriculture. Land Use Pol., 16: 193-205.

Rosen C. J. \& Allan, D. L. (2007): Exploring the benefits of organic nutrient sources for crop production and soil quality. HortTechnology, 17: 422-430.

Sansavini, S., (1997): Integrated fruit production in Europe: research and strategies for a sustainable industry. Sci. Hortic., 68: 25-36.

Woese, K., D. Lang, C. Boess \& Bogl, K. W. (1997): A comparison of originally and conventionally grown foods Results of a review of the relevant literature. J. Sci. Food Agr., 74: 281-293. 